\title{
A FEASIBILITY STUDY OF USING COMPOSITE REINFORCEMENT IN TRANSPORT AND POWER INDUSTRY STRUCTURES
}

\author{
Egidijus Vanagas ${ }^{1}$, Romualdas Kliukas ${ }^{2}$, Ona Lukoševičienè ${ }^{3}$, Pavlo Maruschak ${ }^{4}$, \\ Andrius Patapavičius ${ }^{5}$, Algirdas Juozapaitis ${ }^{6}$ \\ 1,2,3,5 Dept of Strength of Materials and Engineering Mechanics, \\ Vilnius Gediminas Technical University, Lithuania \\ ${ }^{4}$ Dept of Industrial Automation, Ternopil Ivan Pul'uj National Technical University, Ukraine \\ ${ }^{6}$ Dept of Bridges and Special Structures, Vilnius Gediminas Technical University, Lithuania
}

Submitted 5 July 2016; resubmitted 21 April 2017; accepted 7 May 2017

\begin{abstract}
About 92\% of Lithuanian bridges are made of reinforced concrete. Therefore, the problem of increasing the reliability and service life of their structures is most important for ensuring effective operation of transport buildings. The main factor causing transport building structures' failure is associated with high water permeability and low resistance to attack by corrosive media of concrete used in construction. Ports, bridges, tunnels, viaducts make a group of transport structures strongly attacked by the aggressive media, e.g. cold air, water, ice, salts, etc. Though the members of these structures (e.g. columns, beams) are usually designed for 50 years of service, they often require a major overhaul or strengthening, when less than the half of this period has passed. Most of the damaged structures are the destroyed protective concrete layer and the corroded steel reinforcement. The corrosion of steel reinforcement is the main problem, causing the decrease of strength in the structures' and their brittle failure. Now, composite reinforcement is the alternative material used for reinforcing in the considered structures. Its mechanical properties, including the tensile strength and resistance to the attack of aggressive media, are similar to or even better than those of commonly used steel reinforcement. The experimental data on using composite reinforcement in the compression members or in the compressed zones of flexural members of the structures are lacking. Therefore, most of design codes do not mention or even do not recommend using composite reinforcement in these cases. The paper presents the analysis of the possibilities of using composite reinforcement in transport and power industry structures.
\end{abstract}

Keywords: composite reinforcement; columns; circular cross-section; strength; economic comparative analysis.

\section{Introduction}

Circular cross-section reinforced concrete columns are often used in structures of ports, bridges, tunnels. Generally, for the instalment of these constructions steel reinforcement is being used. Corrosion of steel reinforcement is the main and one of the biggest problems reducing the durability of these structures and it is a reason of fragile disintegration of these structures (Fig. 1). In the current period, the composite reinforcement is an alternative material for the production of reinforced concrete structures the mechanical characteristics of which are equal to or even better in comparison of the commonly used steel reinforcement characteristics, including tensile strength and resistance to corrosion at

This article has been corrected since first published. Please see the statement of correction (DOI:10.3846/16484142.2017.1358932 of the erratum). the extremely aggressive environment. The mechanical strength and durability of reinforced concrete structures can considerably decrease in time because of overload or frequent violation of service conditions and due to the attack by the aggressive media. Concrete strength is a major factor, ensuring the safety, as well as economic maintenance and operation of concrete structures. However, many other influencing factors should be also taken into consideration in the design, construction and use of concrete structures. The corrosion of steel reinforcement of the reinforced concrete, which is caused by low concrete density and freezing resistance, as well as a thin protective concrete layer and the attack by aggressive media (e.g. solar radiation, wind, moisture soaking and drying of concrete, its freeze-thaw cycles and saltsaturated ground water), is the main process, leading to concrete structures' failure. Besides, their manufacture, transportation and construction can also bring about some adverse effects, causing concrete microcracking.

Corresponding author: Ona Lukoševičienè

E-mail: ona.lukoseviciene@vgtu.lt

Copyright $\odot 2017$ Vilnius Gediminas Technical University (VGTU) Press

http://www.tandfonline.com/TRAN 

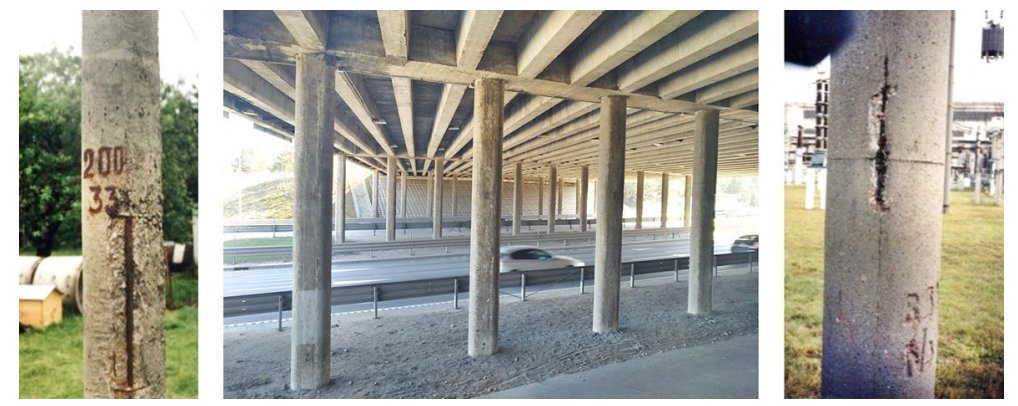

Fig. 1. Circular cross-section reinforced concrete structures damaged by corrosion
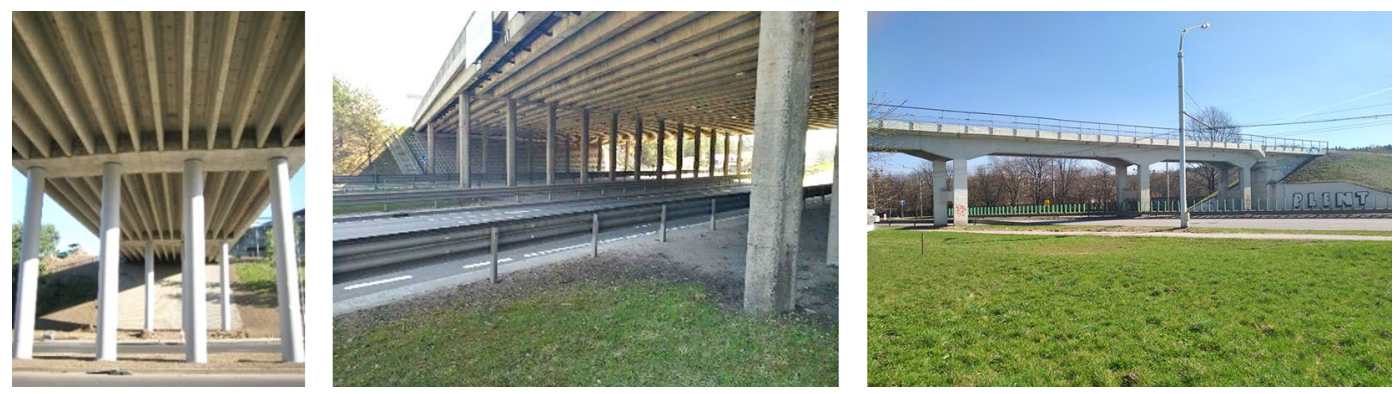

Fig. 2. The transport industry structures operating in highly aggressive media

The structures of transport industry (e.g. ports, bridges, tunnels, viaducts) belong to the group of structures most heavily attacked by the aggressive media (Fig. 2). Though the members of these structures (i.e. columns, beams) are usually designed for 50 years of service, they often need an overhaul of strengthening, when less than a half of this period has passed. Besides, about $92 \%$ of Lithuanian bridges consist of reinforced concrete structures, which implies that the increase in their reliability and strength is a highly important problem for construction in the transport sector.

\section{Composite Reinforcement}

To increase the resistance of steel reinforcement to severe weather conditions and the attack by the aggressive medium, zinc-coated steel reinforcement has been used in the construction of concrete bridges since 1960. However, the use of this type of reinforcement was suspended because electrolysis applied in the process of its manufacturing destroyed the zinc-coated protective reinforcement layer (Kaklauskas et al. 2012).

Later, since 1970, efforts have been made to protect steel reinforcement from corrosion by covering it with epoxy resin, though it has not helped to solve the problem.

The corrosion of steel reinforcement is the problem associated with the material, rather than the structure. Therefore, the best solution to this problem is to change the material used (You et al. 2015).

In the past decades, composite materials have gained wider application in construction. The main factor, stimulating the search for alternatives to steel reinforcement, is associated with steel reinforcement corrosion and the related high maintenance costs.
The main components of Fibre Reinforced Polymer (FRP) are fibre filaments of various materials impregnated with polymer resin (Fig. 3) (Kaklauskas et al. 2012). Fibre strands impart the required properties (i.e. strength and stiffness) to the reinforcing material, while polymer resin combines fibres into a complex whole, thereby ensuring the FRP integrity.

FRP is commonly made of carbon, glass, basalt or aramid fibres. Fibre properties largely determine the FRP properties as a whole. Physical and mechanical properties of FRP are presented in Table 1.

The properties of FRP largely depend on the properties of the fibre filament used in the production of FRP, polymer resin properties and production technology. The properties of FRP commonly used in construction as a reinforcing material are presented in Table 2.

In addition to high resistance to corrosion, a composite reinforcement system has a high tensile strength and small mass, as well as being magnetically neutral and easily worked (i.e. cut into sections on the construction site). However, composite reinforcement has some drawbacks, limiting it application area, which are as follows: a relatively high cost, low modulus of elasticity,

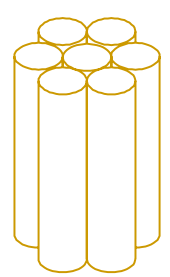

The fiber strands

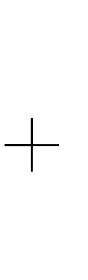

Polymer resin

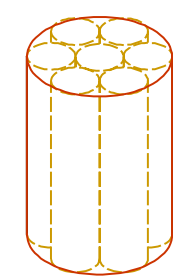

FRP
Fig. 3. Structure of the FRP 
Table 1. Physical and mechanical properties of FRP (Kaklauskas et al. 2012)

\begin{tabular}{|l|c|c|c|c|c|c|}
\hline \multicolumn{1}{|c|}{ FRP type } & $\begin{array}{c}\text { Density } \\
{\left[\mathrm{kg} / \mathrm{m}^{3}\right]}\end{array}$ & $\begin{array}{c}\text { Tensile } \\
\text { strength }[\mathrm{MPa}]\end{array}$ & $\begin{array}{c}\text { Elasticity } \\
\text { modulus } \\
{[\mathrm{GPa}]}\end{array}$ & $\begin{array}{c}\text { Ultimate } \\
\text { tensile } \\
\text { strains }[\%]\end{array}$ & $\begin{array}{c}\text { Thermal expansion } \\
\text { coefficient } \\
{\left[10^{-6} / \mathrm{C}^{\circ}\right]}\end{array}$ & $\begin{array}{c}\text { Poisson's } \\
\text { ratio }\end{array}$ \\
\hline E-glass & 2500 & 3450 & 72.4 & 2.4 & 5.0 & 0.22 \\
\hline S-glass & 2500 & 4580 & 85.5 & 3.3 & 2.9 & 0.22 \\
\hline AR-glass & 2270 & $1800-3500$ & $70-76$ & $2.0-3.0$ & - & - \\
\hline Carbon (usual) & 1700 & 3700 & 250 & 1.2 & from -0.6 to -0.2 & 0.2 \\
\hline Carbon (high elasticity modulus) & 1950 & $2500-4000$ & $350-800$ & 0.5 & from -1.2 to -0.1 & 0.2 \\
\hline Carbon (high strength) & 1750 & 4800 & 240 & 1.1 & from -0.6 to -0.2 & 0.2 \\
\hline Aramid (Kevlar 149) & 1440 & 3450 & 175 & 1.4 & -2.0 longitudinal \\
59 radial & 0.35 \\
\hline Aramid (Technora H) & 1390 & 3000 & 70 & 4.4 & -6.0 longitudinal \\
59 radial & 0.35 \\
\hline Aramid (SVM) & 1430 & $3800-4200$ & 130 & 3.5 & - & - \\
\hline Basalt (Albarrie) & 2800 & 4840 & 89 & 3.1 & & - \\
\hline
\end{tabular}

Table 2. The properties of composite and steel reinforcement, when fibre volume part is equal 0.5-0.75 (Kaklauskas et al. 2012)

\begin{tabular}{|l|c|c|c|c|}
\hline \multirow{2}{*}{ Property } & \multicolumn{4}{c|}{ Material } \\
\cline { 2 - 5 } & Steel & Glass fibre & Carbon fibre & Aramid fibre \\
\hline Elasticity modulus along fibre [GPa] & 200 & $35-60$ & $100-580$ & $40-125$ \\
\hline Tensile strength [MPa] & $450-700$ & $450-1600$ & $600-3500$ & $1000-2500$ \\
\hline Ultimate failure strain [\%] & $5-20$ & $1.2-3.7$ & $0.5-1.7$ & $1.9-4.4$ \\
\hline
\end{tabular}

brittle failure, strength decrease with time and the lack of design specifications. Some of these drawbacks can be compensated for by the application of special types of composite reinforcement systems. For example, the cost of a composite reinforcement system is only slightly higher than that of steel reinforcement, when glass fibre reinforcing bars are used. However, the low modulus of elasticity and strength decrease with time pose some additional problems to the designers of the structures. On the other hand, carbon fibre bars have high moduli of elasticity and tensile strength, which does not vary considerably with time, as well as high fatigue resistance, but their cost is much higher than that of steel bars. The problem of brittle failure could be partially solved by combining various fibres, however, in this case, the production would be more complicated and expensive.

Composite materials are not resistant to high temperatures. High temperatures primarily affect the FRP matrix (polymer resin). Under low temperatures $\left(90-180^{\circ} \mathrm{C}\right)$, the matrix plasticizes, which reduces its effectiveness due to the interaction with the fibre, decreasing its adhesion to concrete (Wu 1990; Kaklauskas et al. 2012). Finally, the structure can disintegrate or suffer heavy deformations. Polymer reinforcement is not recommended for use in reinforced concrete structures, which are either constantly exposed to high temperatures or are at high risk of exposure to high temperatures in operation.

Using new materials in real building structures is always associated with risks. In recent years, the study of concrete structures with composite reinforcement sys- tems and their use in real buildings has become the focus of many researchers all over the world (Alsayed et al. 1999; Hadi et al. 2016; Kaklauskas et al. 2012; Skuturna, Valivonis 2016; Tobbi et al. 2014). Though great experience has been gained in the world in design, construction and use of structures with composite reinforcement systems, their design is still a complicated problem because of a great variety and specific mechanical properties of such structures.

\section{Structural Members of Buildings and Civil Engineering Works with Steel and Composite Reinforcing Bars}

In the construction areas associated with transport, power, industrial and hydrotechnical engineering, concrete structures with annular and circular cross-sections are widely used. They include power line poles, foundation piles, the members of bridges, viaducts, sea and port structures, smoke stacks, TV towers, etc. Rather high elasticity, crack resistance and durability of the structures with an annular cross-section are the characteristics, requiring a wider use of these structures in various areas of construction and other fields. The improvement of physical and mechanical concrete properties and the introduction of new composite reinforcement systems is important for developing and using the structures with this type of reinforcement.

The behaviour of concrete members reinforced with FRP bars has been the focus of many studies in recent years. Nowadays, several codes and design guide- 
lines are available for designing concrete structures reinforced with FRP bars under flexural and shear loads. Meanwhile, the research works, investigating the axial behaviour of reinforced concrete columns with FRP bars are few (Afifi et al. 2014a, 2014b, 2015; Tobbi et al. 2014). Due to the lack of research into the axial behaviour of FRP reinforced concrete columns, North American codes and design guidelines do not recommend using FRP bars as longitudinal reinforcement in columns to resist compressive stresses.

It is noteworthy that the need for further investigation of the possibilities of using composite reinforcing bars in columns for determining their behaviour and specifying the scope of application of this type of reinforcement is emphasized in ACI 440.1R-06 design specifications. It is also emphasized that CAN/CSA-S6-06 design specifications allow for using composite reinforcing bars in the compression zones of flexural members, if the contribution of this type of reinforcement to the total carrying capacity of the structure is not accounted.

However, the reliability and economic efficiency of a structure depends not only on its carrying capacity (i.e. the maximal compressive force or bending moment, which the structure can withstand), but also on its durability. The durability as the main quality indicator of the structures should be always evaluated, when structures are subjected to attack by the aggressive medium in service conditions.

\subsection{The Effect of Lateral Reinforcement on the Compression Members' Performance}

Corrosion of reinforcement is the main cause of power line poles' failure. Lateral (spiral) reinforcement near the surface of the pole is damaged by corrosion first. Then, the lateral reinforcement bars subjected to compression lose their equilibrium, and the structure fails. One of the effective methods to avoid lateral reinforcement corrosion is using composite spiral reinforcement. As mentioned above, composite reinforcing bars have high tensile strength, while lateral (spiral) reinforcement is subjected to tensile strains in structures under compression.

It is well known, that lateral (transverse) reinforcement increases concrete strength, preventing the formation of lateral deformations by creating the confinement effect. Considère (1902) observed that lateral pressure increases the strength of concrete cylinders. He offered to use continuous spiral windings as reinforcement for concrete cylinders. Abramov (1907) suggested use wire mesh for concrete reinforcement, while German scientists Schinke and Löser (1907), recommended use thin metal sheets for transverse reinforcement.

The first investigations of lateral reinforcement of structural members have already demonstrated that it can increase concrete strength and the longitudinal ultimate strain, as well as ensuring delayed fracture. It has been also found that spiral reinforcement is more effective than grid reinforcement.

The concrete strength in the column confinement depends on the properties of concrete and the confine- ment. The main concrete properties are its strength and longitudinal compressibility. A confinement is described by the reinforcement ratio of the spiral wire $\rho_{\text {cir }}$, pitch $s$ and spiral diameter $d_{e f}$ as well as yield $f_{y, c i r}$ and strength $f_{s, \text { cir }}$ limits.

According to Considère (1902), the strength of concrete under lateral pressure can be determined by the formula:

$$
f_{c, \text { red }}=f_{c}+\psi \cdot p
$$

where: $f_{c}$ is specified compressive strength of plain concrete; $\psi \approx 4.8$ is the effectiveness coefficient of lateral pressure.

Assuming uniform spiral pressure on the lateral surface and taking into account the equilibrium of the spiral half-turn, we get that the intensity of the lateral pressure may be expressed as follow:

$$
p=\frac{2 \cdot f_{s, c i r} \cdot A_{s, c i r}}{d_{e f} \cdot s}
$$

where: $f_{s, c i r}$ is the tension strength of spiral; $A_{s, c i r}$ denote the cross-section area of the spiral wire.

According to (1) and (2), the axial compressive force may be expressed as follows:

$$
N=f_{c} \cdot A_{e f}+\frac{\psi}{2} \cdot A_{\text {cir }} \cdot f_{s, c i r}
$$

where concrete cross-section area restricted by spiral may be calculated by equation $A_{e f}=\frac{\pi \cdot d_{e f}^{2}}{4}$, and reduced cross-section area of spiral may be expressed $A_{c i r}=\frac{\pi \cdot d_{e f}}{s} \cdot A_{s, c i r}$. The value $\frac{\psi}{2}$ in Eq. (3) is usually denoted by the effectiveness coefficient $\phi$. It shows how much more effective the spiral column confinement compared to longitudinal reinforcement of the same class. The strength of concrete structures in the stressed state is calculated by the formulas, where lateral effect of transverse reinforcement is accounted for by the coefficient $\phi$. In various works, this coefficient varies from 2 to 5.3 (Abramov 1907; Candappa et al. 2001; Richart et al. 1928; Tobbi et al. 2014).

According to SNiP 2.03.01-84 design code (Russian Standard) the strength of concrete in axially loaded members of a circular cross-section with spiral reinforcement may be expressed:

$$
f_{c, \text { red }}=f_{c}+2 \cdot \rho_{\text {cir }} \cdot f_{s, \text { cir }} \cdot\left(1-\frac{7.5 e_{o}}{d_{e f}}\right) \text {. }
$$

Comparing Eqs (4) and (1) and taking into account Eq. (2), as well as assuming the eccentricity $e_{0}$ of the longitudinal force equal to $e_{0}=0$, we get that the coefficient $\phi=2$.

The examination of the work of reinforced concrete members with lateral welded wire mesh reinforcement under centric and eccentric compression has shown that weld mesh reinforcement helps to considerably increase the strength of reinforced concrete members both under centric and eccentric pressure because it restricts the development of transverse deformations. 
Mesh reinforcement also largely increases ultimate concrete deformability. At the failure stage, stress redistribution is ensured in the compressed zones of eccentrically compressed members, allowing more effective use of the mesh bars.

In calculating the strength of the cross-sections of the members laterally reinforced with weld meshes, the increased concrete strength, due to the effect of lateral reinforcement, and the reduced cross-section area of the concrete member, because of the separation of the protective concrete layer before the failure of the structure.

The variable value of the efficiency coefficient of lateral reinforcement should be assumed, depending on the proportion of lateral reinforcement. The protective concrete layer in the centrically or eccentrically compressed members with lateral reinforcement separates, when concrete reaches the ultimate deformability, matching its deformability in ordinary hooped concrete members.

Increasing the transverse reinforcing bar cross-section from 6.4 to $12.7 \mathrm{~mm}$ increases the column's carrying capacity by $6 \%$, while decreasing the transverse reinforcement step from 120 to $40 \mathrm{~mm}$ increases the column carrying capacity by $3 \%$ (Kudzys et al. 1993).

The examination of the experimental results (Afifi et al. 2014a) shows that increasing the cross-section of the transverse reinforcement and reducing the transverse reinforcement step could probably increase the column carrying capacity up to $10 \%$, and this increase would not be assessed by any of the above-mentioned calculation methods.

Transverse reinforcement, restricting the development of transverse deformations, increases the concrete strength by creating the confining effect. Researchers from Vilnius Gediminas Technical University (Lithuania) carried out the research on axially loaded circular cross-section elements reinforced with spiral reinforcement (Kudzys et al. 1993).

The spiral efficiency coefficient may be calculated by the formula:

$$
\alpha_{c i r}=\frac{f_{c, c i r}}{f_{c}}=0.81+0.9 \cdot \rho_{c i r}-0.6 \cdot \rho_{c i r}^{2},
$$

where: $f_{c, c i r}$ is the compressive concrete strength of reinforced member; $f_{c}$ is specified compressive concrete strength of plane concrete; $\rho_{c i r}=0.25-1.25 \%$ is the percentage reinforcement ratio for spiral wire (Kudzys et al. 1993).

It has been confirmed that using wire reinforcement with a spiral pitch $s<100 \mathrm{~mm}$ causes concrete compressibility increase up to $15-20 \%$. A positive effect of the spiral wire on the spun concrete strength, when $f_{c}$ is from 47 to $50 \mathrm{~N} / \mathrm{mm}^{2}$, is shown in Fig. 4 .

This relatively slight influence of the spiral on the strength of tubular concrete can be attributed to the fact that the tubular sample in the strained state can be described as a two-dimensional (plane) body rather than a three-dimensional one. It is known that flat concrete double-axis compression virtually has no effect on its strength, which is close to the cylinder's strength.

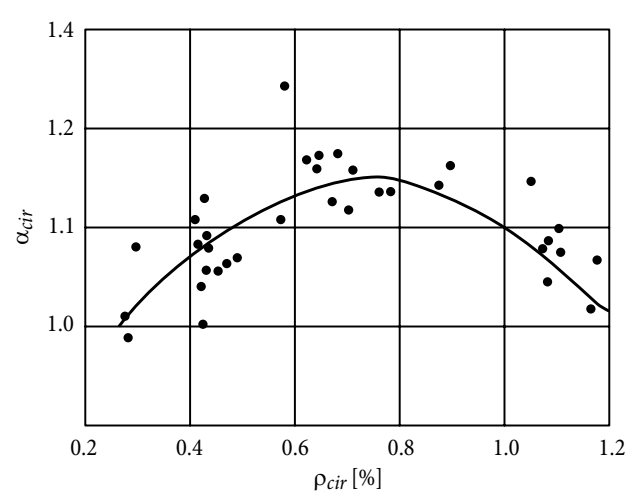

Fig. 4. The effect of the spiral wire reinforcement ratio $\rho_{\text {cir }}$ on the efficiency coefficient of annular reinforcement $\alpha_{c i r}$ by Eq. (5)

The experimental study has shown that the carrying capacity of axially loaded solid members can be significantly increased by using the transverse spiral reinforcement. The increase in concrete strength within the confinement (a spiral) depends on the intensity of transverse reinforcement, as well as the spiral material strength and deformation (Kudzys et al. 1993).

Taking into consideration the results obtained in the experimental investigations, which are described above, the calculation of the carrying capacity of concrete members, additionally reinforced with transversed reinforcement, should involve:

- the calculation of the ultimate carrying capacity, taking into account the increase in concrete strength and separation of the protective concrete layer;

- the calculation of the ultimate carrying capacity, not taking into account the effect of transverse reinforcement on concrete strength and not reducing the area of the member's cross-section, reduced due to the separation of the protective concrete layer.

\subsection{Design Requirements for Carrying Capacity of Concrete Columns Reinforced with Steel or FRP Bars}

Several codes and design guidelines are now available for designing concrete structures reinforced with FRP bars under flexural and shear loads. However, due to a lack of research, design codes in different countries do not take into account the compressed FRP reinforcement work or even do not recommend use the bars of this type as longitudinal reinforcement elements in the compression or bending zones of columns (Afifi et al. 2014b) (Table 3).

\subsection{Assessing FRP Contribution to the Calculation Results of Concrete Columns Reinforced with Longitudinal Reinforcing FRP Bars}

Researchers from the Canadian University of Sherbrooke performed the experimental research on axially loaded concrete columns reinforced with FRP (Afifi et al. 2014a) and suggested the following calculation of 
Table 3. Design codes' requirements for carrying capacity of steel and FRP reinforced columns

\begin{tabular}{|c|c|c|c|}
\hline $\begin{array}{l}\text { Design code; } \\
\text { Country }\end{array}$ & $\begin{array}{c}\text { Concrete columns reinforced } \\
\text { with steel bars } \\
\end{array}$ & $\begin{array}{c}\text { Concrete columns } \\
\text { reinforced with FRP bars }\end{array}$ & Notes \\
\hline Eurocode 2; EU & $N=\alpha \cdot f_{c} \cdot A_{c}+f_{s} \cdot A_{s}$ & Not specified & \multirow{6}{*}{$\begin{array}{l}\alpha \text { is reduction factor of the } \\
\text { concrete strength; } \\
f_{c} \text { is specified compressive strength } \\
\text { of concrete; } \\
A_{c} \text { is gross area of concrete section; } \\
f_{s} \text { is specified yield strength of } \\
\text { longitudinal reinforcement; } \\
A_{s} \text { is area of longitudinal } \\
\text { reinforcement; } \\
\varphi \text { is the strength reduction factor; } \\
N_{o} \text { is a nominal carrying capacity } \\
\text { for axial load; } \\
\alpha_{1} \text { is the ratio of the average stress } \\
\text { in the rectangular compression } \\
\text { member to the specified concrete } \\
\text { strength; } \\
\varphi_{c} \text { is the resistance coefficient for } \\
\text { concrete; } \\
\varphi_{s} \text { is the resistance coefficient for } \\
\text { non-prestressed reinforcing bars; } \\
k \text { is the strength reduction factor } \\
\text { for unexpected eccentricities, } \\
\text { which equal to } 0.8\end{array}$} \\
\hline SNiP 2.03.01-84; RU & $N=f_{c} \cdot A_{c}+f_{s} \cdot A_{s}$ & Not specified & \\
\hline STR 2.05.05:2005; LT & $N=f_{c} \cdot A_{c}+f_{s} \cdot A_{s}$ & Not specified & \\
\hline ACI 318-11; US & $\begin{array}{l}\text { For columns with spiral reinforcement } \\
\varphi=0.75 \text { : } \\
N=\varphi \cdot N_{0}=0.85 \cdot \varphi \times \\
\left(0.85 \cdot f_{c} \cdot\left(A_{c}-A_{s}\right)+f_{s} \cdot A_{s}\right) \\
\text { For hooped columns } \varphi=0.65: \\
N=\varphi \cdot N_{0}=0.8 \cdot \varphi \times \\
\left(0.85 \cdot f_{c} \cdot\left(A_{c}-A_{s}\right)+f_{s} \cdot A_{s}\right)\end{array}$ & $\begin{array}{l}\text { The USA design } \\
\text { code either does not } \\
\text { recommend using } \\
\text { FRP reinforcement in } \\
\text { columns or requires } \\
\text { that the strength of the } \\
\text { FRP bar in compression } \\
\text { should be ignored }\end{array}$ & \\
\hline $\begin{array}{l}\text { CAN/CSA-A23.3-04 } \\
\text { (R2010); CA }\end{array}$ & $\begin{array}{l}\text { For columns with spiral reinforcement: } \\
N=0.85 \cdot\left(\alpha_{1} \cdot \varphi_{c} \cdot f_{c} \times\right. \\
\left.\left(A_{c}-A_{s}\right)+\varphi_{s} \cdot f_{s} \cdot A_{s}\right) \\
\text { For hooped columns: } \\
N=0.8 \cdot\left(\alpha_{1} \cdot \varphi_{c} \cdot f_{c} \times\right. \\
\left.\left(A_{c}-A_{s}\right)+\varphi_{s} \cdot f_{s} \cdot A_{s}\right)\end{array}$ & Not $\mathrm{sp}$ & \\
\hline CAN/CSA-S6-06; CA & $\begin{array}{l}N=k \cdot\left(\alpha_{1} \cdot \varphi_{c} \cdot f_{c} \times\right. \\
\left.\left(A_{c}-A_{s}\right)+\varphi_{s} \cdot f_{s} \cdot A_{s}\right)\end{array}$ & $\begin{array}{l}\text { Strength of the FRP bar } \\
\text { in compression should } \\
\text { be ignored: } \\
N=\alpha_{1} \cdot \varphi_{c} \cdot f_{c} \cdot\left(A_{c}-A_{s}\right)\end{array}$ & \\
\hline
\end{tabular}

the theoretical ultimate strength for the FRP reinforced concrete columns:

$$
\begin{aligned}
& N_{(a)}=N_{c}+N_{f(a)}= \\
& 0.85 \cdot f_{c} \cdot\left(A_{c}-A_{f}\right)+\alpha_{c} \cdot f_{f n} \cdot A_{f},
\end{aligned}
$$

where: $N_{c}$ is axial force part of specified concrete columns; $N_{f(a)}$ is axial force part of FRP reinforcement; $f_{f n}$ is the ultimate tensile strength of FRP reinforcement; $A_{f}$ is the cross-section area of FRP reinforcement. A new factor $\alpha_{c}$ was introduced to account for the decrease in the compressive strength of the FRP bar as a function of its tensile strength. Based on the experimental results, this factor was found to be equal to 0.25 .

Besides, it was compared with the calculated value of axial force $N_{(a)}$, assuming the contribution of GFRP bars in compression to be equal to $35 \%$ of the GFRP tensile strength, as suggested by Kobayashi and Fujisaki (1995), Mallick (2007) and Wu (1990), then:

$$
\begin{aligned}
& N_{(b)}=N_{c}+N_{f(b)}= \\
& 0.85 \cdot f_{c} \cdot\left(A_{c}-A_{f}\right)+0.35 \cdot f_{f n} \cdot A_{f},
\end{aligned}
$$

where: $N_{f(b)}$ is axial force part of FRP reinforcement.

\section{The Comparative Analysis of Experimental and Theoretical Results}

In addition to the recommendations provided in design codes of different countries for using FRP in the compression members or compressed areas of flexural members, many experimental studies of axially loaded columns with FRP (fibreglass, carbon fibre, etc.) have been made in Canada (Afifi et al. 2014a).

It should be noted that all the above-mentioned design rules (Table 3 ) do not recommend using FRP in the compression members, and the calculations do not take into account the contribution of this reinforcing material to the overall construction work, i.e. the carrying capacity of the structure is calculated based only on the properties of concrete. However, it should be noted that the experimental studies presented in Fig. 5a show that the carrying capacity of columns reinforced with FRP from 1.15 to 1.30 times that of a non-reinforced column.

The experimental results were used for the analysis of the calculation methods of axially loaded columns reinforced with FRP (Afifi et al. 2014a). Where the research was aimed at determining the strength and deformation of axially loaded circular cross-section concrete members reinforced with FRP. The data obtained in the comparative analysis of experimental and theoretical results are presented in Fig. 5b. Theoretically calculated results differed in a wider range from the experimentally determined results based on using the Canadian design code recommendations (Fig. 5b).

The comparison of the results has shown that analytically calculated values closely matched the experimentally determined values, when the calculation algorithm model of Afifi et al. (2014a), assessing the contribution of FRP to the carrying capacity of the structure, was used. Analytical and experimental carrying capacity values were obtained based on the recommendations found in CAN/CSA-S806-12, ACI 318-11 and Afifi et al. (2014a) and differed from them by up to $20 \%$. 

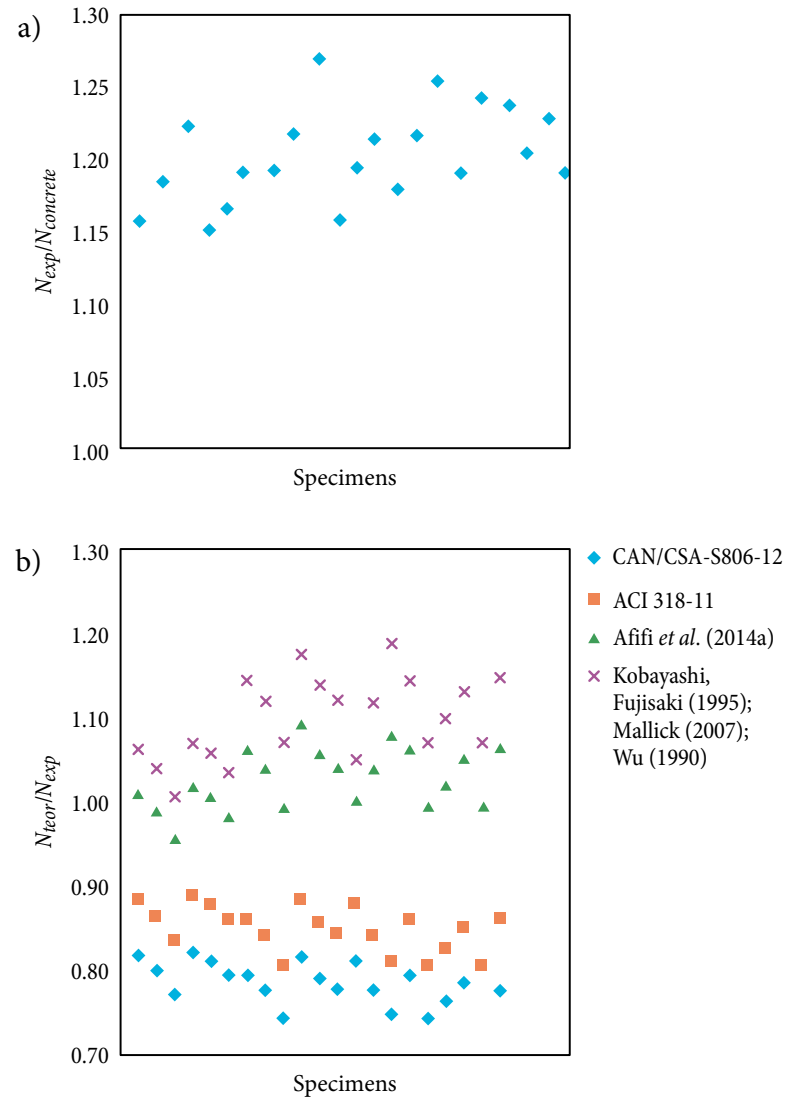

Fig. 5. $N_{\text {exp }}$ ratio of axial compression columns reinforced with composite GFRP and CFRP longitudinal and transverse reinforcing bars versus that of a non-reinforced concrete column $N_{\text {concrete }}\left(\right.$ a); theoretical values $N_{\text {teor }}$ of carrying capacity calculated according to various recommendations versus the experimentally determined values $N_{\exp }$ (b)

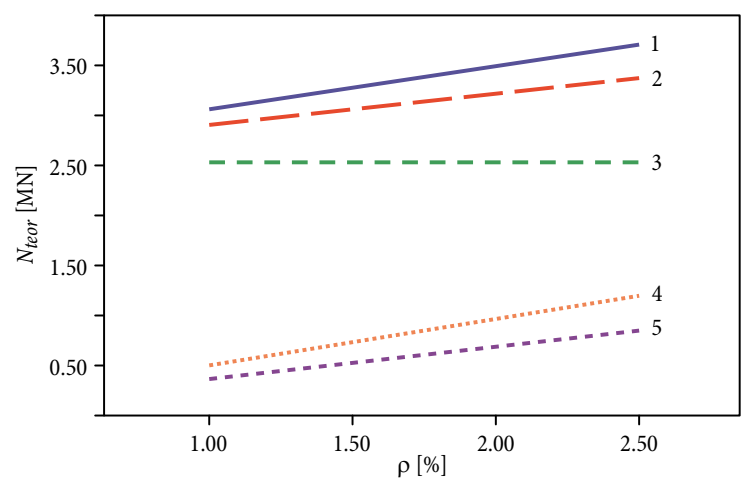

Fig. 6. The longitudinal reinforcement ratio $\rho$, the dependence on theoretical axial force $N_{\text {teor }}$ calculated by a different calculation algorithm by Eq. (7) [line - 1] and Eq. (6) [line - 2], where the carrying capacity of concrete $N_{c}$ [line - 3] and longitudinal reinforcement $N_{f(b)}$ [line - 4] and $N_{f(a)}$ [line - 5]

For the analysis of the calculation models we devided the Eqs (6) and (7) into two parts, representing the carrying capacity of concrete $N_{c}$ and longitudinal reinforcement $N_{f(a)}$ and $N_{f(b)}$ respectively. The results of models analysis are presented in Fig. 6.
The axial load $N_{(a)}$, applied to FRP comprises from 15 to $30 \%$ of the load-carrying capacity of the column, depending on the FRP factor of the longitudinal reinforcing bars. It should also be noted that when the calculation algorithm model for axial load $N_{(b)}$, by Eq. (7) suggested by Kobayashi and Fujisaki (1995), Mallick (2007) and $\mathrm{Wu}(1990)$ is used, the contribution of transverse reinforcement to carrying capacity of the column varies from 25 to $35 \%$.

Although the theoretical and experimental results demonstrated close matching, when the calculation algorithm proposed by Eq. (6) Afifi et al. (2014a) was used, it should be noted that this calculation model, as well as the calculation algorithm model by Eq. (7) of Kobayashi and Fujisaki (1995), Mallick (2007) and Wu (1990), does not account for the effect of transverse reinforcement on the carrying capacity of the structure.

\section{The Comparative Analysis of Economic Efficiency of Columns Reinforced with Composite and Steel Reinforcing Bars}

As mentioned above, the damages usually observed in the concrete structures of transport buildings include the destroyed protective concrete layer and the corroded steel reinforcing bars. These damages are the signs of a possible failure of the structure. To avoid it and repair the structure, large investments are required.

The cost of ordinary concrete columns reinforced with steel includes the cost of materials (reinforcing bars and concrete), equipment and work payment (Fig. 7).

The contribution of steel reinforcement to the cost of ordinary concrete columns makes $28-30 \%$ (Fig 7a), while the contribution of the composite reinforcement

a)

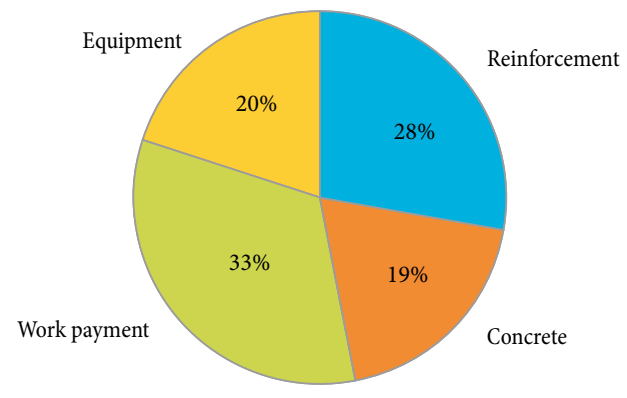

b)

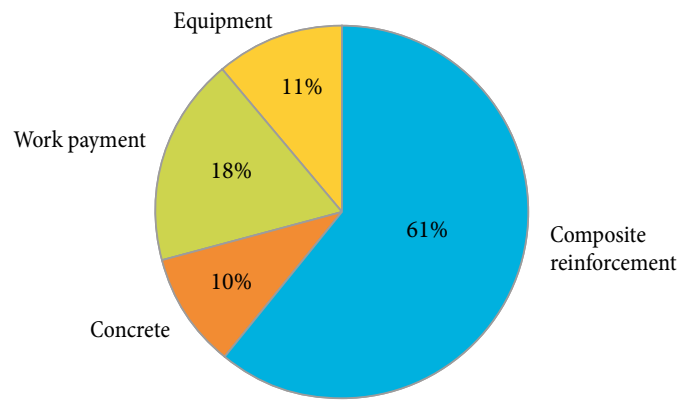

Fig. 7. Production cost distribution of ordinary concrete columns reinforced with steel bars (a) and columns reinforced with GFRP bars (b) 
reaches about $61 \%$ for columns with this type of reinforcement (i.e. it is about twice as large). The results of the comparative analysis of columns from this perspective are given in Table 4.

For cost analysis of the reinforced concrete columns, five columns have been selected, whose carrying capacity was determined experimentally (Afifi et al. 2014a) and differed by $5 \%$. The initial letter of the specimen's name denotes the material of longitudinal reinforcement (S steel, C CFRP, G GFRP), while the second letter denotes the material used for transverse reinforcement and the number means the diameter of the column $(\mathrm{mm})$. The height of the selected columns is $1500 \mathrm{~mm}$.

The most economical column, requiring the smallest expenses, is the column with longitudinal or transverse steel reinforcement. However, as mentioned above, due to the damaged protective concrete layer and corrosion of reinforcement, it often needs an expensive repair, even when the design operation period has not elapsed yet.

The economic-financial calculations of columns, fabricated using a composite carbon fibre (C-C-300) and glass fibre reinforcement (G-G-300) (for longitudinal and transverse reinforcement), have shown that their cost is by $1910 \%$ and $83 \%$ higher than that of the steel reinforced columns (S-S-300) (Table 4) respectively. Therefore, it can be concluded that these columns should be used only in the operational conditions, when their durability is insufficient, and they require complicated and expensive repairs (e.g. on the oil production platforms, in hydraulic engineering buildings, etc.).

It should be noted that transverse steel reinforcement is more often damaged by corrosion in transport and power engineering buildings. Therefore, the performed comparative economic-financial analysis of columns with longitudinal reinforcement made of steel, and transverse reinforcement made of composite glass fibre (S-G-300) and carbon fibre (S-C-300), which is re- sistant to the attack by the aggressive media, has shown that their cost is 3 and $281 \%$ higher than that of the columns with steel reinforcement (Table 4) respectively.

However, this cost difference can be compensated for by using annular cross-section columns rather than solid circular cross-section columns, thereby reducing the amount of concrete required for column production (Table 5).

The cost of an annular cross-section column with longitudinal steel reinforcement and that with transverse glass fibre reinforcement (product S-G-300-1) is 7.7\% lower compared with the cost of solid circular crosssection column reinforced in a similar way (product S-G-300).

For making more detailed conclusions, further research into the carrying capacity of annular cross-section columns with composite reinforcement is needed.

\section{Conclusions}

Transport and power industry structures make a group of structures strongly attacked by the aggressive media, e.g. frost, water, ice, salts, etc. Usually, these structures fail before their design operation period elapses. Most of the damages are the destroyed protective concrete layer and the corroded steel reinforcement. Composite reinforcing bars can be used as the alternative material for structures' reinforcement. Design codes of different countries do not take into account the work of FRP reinforcing bars and even do not recommend them to be used for longitudinal reinforcement of columns in compression or flexural members. However, the analysis of the calculation methods based on the experimental studies, which can be found in the literature, has shown that they do not take into account the contribution of transverse reinforcement to the carrying capacity of columns.

Table 4. The cost of columns with steel and composite reinforcement

\begin{tabular}{|c|c|c|c|c|c|}
\hline Specimen & $\begin{array}{c}N_{\text {exp }}[\mathrm{MN}] \\
\text { (experimental } \\
\text { results) }\end{array}$ & $\begin{array}{c}\text { Cost of column } \\
\text { reinforcement }[€]\end{array}$ & $\begin{array}{c}\text { Cost difference between } \\
\text { composite and steel } \\
\text { reinforcement [\%] }\end{array}$ & $\begin{array}{c}\text { The expected cost } \\
\text { of column [€] } \\
\text { (without VAT) }\end{array}$ & $\begin{array}{c}\text { Cost difference between } \\
\text { columns with composite } \\
\text { and steel reinforcement [\%] }\end{array}$ \\
\hline S-S-300 & 3.141 & 13.48 & - & 47.21 & - \\
\hline C-C-300 & 3.147 & 915.20 & 6690 & 948.96 & +1910 \\
\hline G-G-300 & 3.019 & 52.85 & 292 & 86.61 & +83 \\
\hline S-G-300 & - & 15.03 & 11 & 48.79 & +3 \\
\hline S-C-300 & - & 146.00 & 983 & 179.76 & +281 \\
\hline
\end{tabular}

Table 5. The comparative cost analysis of annular cross-section columns with steel and composite reinforcement

\begin{tabular}{|c|c|c|c|c|}
\hline Specimen & $\begin{array}{c}\text { Cost of column } \\
\text { reinforcement [€] }\end{array}$ & $\begin{array}{c}\text { Cost difference between } \\
\text { composite and steel } \\
\text { reinforcement [\%] }\end{array}$ & $\begin{array}{c}\text { Expected cost of column [€] } \\
\text { (without VAT) }\end{array}$ & $\begin{array}{c}\text { Cost difference between columns } \\
\text { with composite and steel } \\
\text { reinforcement [\%] }\end{array}$ \\
\hline S-S-300-1 & 13.48 & - & 41,96 & - \\
\hline C-C-300-1 & 915.20 & 6690 & 945.21 & 2153 \\
\hline G-G-300-1 & 52.85 & 292 & 82.86 & 97 \\
\hline S-G-300-1 & 15.03 & 11 & 45.04 & 319 \\
\hline S-C-300-1 & 146.00 & 983 & 176.01 & 7 \\
\hline
\end{tabular}


The carrying capacity of axially loaded solid members can be significantly increased by using the transverse spiral reinforcement. The increase in concrete strength within the confinement (a spiral) depends on the intensity of transverse reinforcement and spiral material strength, as well as deformation.

Experimental studies are needed to offer theoretical solutions to the problem of carrying capacity calculation of the examined members and to ensure the reliability of structures.

The performed economic analysis has shown that the structures with composite transverse and longitudinal reinforcement are much more expensive than the structures with ordinary reinforcement. Therefore, this type of reinforcement is economically efficient only in structures, which are attacked by the particularly aggressive medium during their service life, while their repair at the stage of operation is complicated and expensive.

In the structures of transport or power engineering, transverse steel reinforcement is damaged by corrosion first. The cost of the columns used in transport or power engineering buildings, which have longitudinal steel reinforcement and transverse reinforcement of composite glass (S-G-300) or corrosion resistant carbon fibre (S-C300 ), also resistant to the attack by aggressive medium, is 3 and $281 \%$ higher than the cost of steel-reinforced columns, respectively.

\section{References}

Abramov, N. M. 1907. Izuchenie svojstv betona v obojme. Mehanicheskaya laboratoriya instituta inzhenerov putej soobshheniya. Sankt-Peterburg (in Russian).

ACI 318-11. Building Code Requirements for Structural Concrete and Commentary.

ACI 440.1R-06. Guide for the Design and Construction of Structural Concrete Reinforced with FRP Bars.

Afifi, M.; Mohamed, H. M.; Benmokrane, B. 2015. Theoretical stress-strain model for circular concrete columns confined by GFRP spirals and hoops, Engineering Structures 102: 202-213. https://doi.org/10.1016/j.engstruct.2015.08.020

Afifi, M. Z.; Mohamed, H. M.; Benmokrane, B. 2014a. Axial capacity of circular concrete columns reinforced with GFRP bars and spirals, Journal of Composites for Construction 18(1). https://doi.org/10.1061/(ASCE)CC.1943-5614.0000438

Afifi, M. Z.; Mohamed, H. M.; Benmokrane, B. 2014b. Strength and axial behavior of circular concrete columns reinforced with CFRP bars and spirals, Journal of Composites for Construction 18(2).

https://doi.org/10.1061/(ASCE)CC.1943-5614.0000430

Alsayed, S. H.; Al-Salloum, Y. A.; Almusallam, T. H.; Amjad, M. A. 1999. Concrete Columns Reinforced by Glass Fiber Reinforced Polymer Rods, in Fourth International Symposium: Fiber Reinforced Polymer Reinforcement for Reinforced Concrete Structures, American Concrete Institute, 103-112.

CAN/CSA-A23.3-04 (R2010). Design of Concrete Structures.

CAN/CSA-S6-06. Canadian Highway Bridge Design Code.

CAN/CSA-S806-12. Design and Construction of Building Components with Fibre-Reinforced Polymers.
Candappa, D. C.; Sanjayan, J. G.; Setunge, S. 2001. Complete triaxial stress-strain curves of high-strength concrete, Journal of Materials in Civil Engineering 13(3).

https://doi.org/10.1061/(ASCE)0899-1561(2001)13:3(209)

Considère, A. 1902. Experimental Research on Reinforced Concrete. McGraw Publishing. 222 p.

Eurocode 2. Design Of Concrete Structures. EN 1992.

Hadi, M. N. S.; Karim, H.; Sheikh, M. N. 2016. Experimental investigations on circular concrete columns reinforced with GFRP bars and helices under different loading conditions, Journal of Composites for Construction 20(4). https://doi.org/10.1061/(ASCE)CC.1943-5614.0000670

Kaklauskas, G.; Bačinskas, D.; Gribniak, V.; Jakubovskis, R.; Ulbinas, D.; Gudonis, E.; Meškènas, A.; Timinskas, E.; Sokolov, A. 2012. Kompozitais armuotos betonines konstrukcijos: vadovelis. Vilnius: Technika. 300 p. https://doi.org/10.3846/1411-S (in Lithuanian).

Kobayashi, K.; Fujisaki, T. 1995. Compressive behavior of FRP reinforcement in non-prestressed concrete members, in Non-Metallic (FRP) Reinforcement for Concrete Structures: Proceedings of the Second International RILEM Symposium (FRPRCS-2), 23-25 August 1995, Ghent, Belgium, 267-274.

Kudzys, A.; Kliukas, R.; Vadlūga, R. 1993. Using high-strength spun concrete and reinforcing steel in compressive structures, The International Conference of High-Strength Concrete, 20-24 June 1993, Lillehammer, Norway, 259-268.

Mallick, P. K. 2007. Fiber-Reinforced Composites: Materials, Manufacturing, and Design. 3rd edition. CRC Press. 638 p.

Richart, F. E.; Brandtzaeg, A.; Brown, R. L. 1928. A study of the failure of concrete under combined compressive stresses, University of Illinois Bulletin 26(12): 1-104.

Schinke, M. G.; Löser, B. 1907. Eine Eisenbetonstudie, Beton und Eisen 6: 151-153, 179-181.

Skuturna, T.; Valivonis, J. 2016. Evaluation of calculation methods used for estimating the ultimate moment resistance of bridge decks reinforced with FRP bars, The Baltic Journal of Road and Bridge Engineering 11(1): 22-34. https://doi.org/10.3846/bjrbe.2016.03

SNiP 2.03.01-84. Betonnye i zhelezobetonnye konstrukcii (in Russian).

STR 2.05.05:2005. Betoniniu ir gelžbetoniu konstrukciju projektavimas. Statybos techninis reglamentas (in Lithuanian).

Tobbi, H.; Farghaly, A. S.; Benmokrane, B. 2014. Strength model for concrete columns reinforced with fiber-reinforced polymer bars and ties, ACI Structural Journal 111(4): 789-798. https://doi.org/10.14359/51686630

Wu, W.-P. 1990. Thermomechanical Properties of Fiber Reinforced Plastic (FRP) Bars: PhD dissertation. West Virginia University, Morgantown, WV, US.

You, Y.-J.; Park, K.-T.; Seo, D.-W.; Hwang, J.-H. 2015. Tensile strength of GFRP reinforcing bars with hollow section, Advances in Materials Science and Engineering 2015: 1-8. https://doi.org/10.1155/2015/621546 